\title{
"Production of fructooligosaccharides by mycelium-bound transfructosylation activity present in Cladosporium cladosporioides and Penicilium sizovae"
}

P. Zambelli, L. Fernandez-Arrojo, D. Romano, P. SantosMoriano, M. Gimeno-Perez, A. Poveda, R. Gandolfi, M. Fernández-Lobato, F. Molinari, F.J. Plou*

Published in:

Process Biochemistry, 49, 2174-2180 (2014)

http://dx.doi.org/10.1016/j.procbio.2014.09.021 


\title{
Production of fructooligosaccharides by mycelium-bound
}

\section{transfructosylation activity present in Cladosporium cladosporioides}

\section{and Penicilium sizovae}

\author{
P. Zambellia, L. Fernandez-Arrojo ${ }^{b}$, D. Romano ${ }^{a}$, P. Santos-Moriano ${ }^{b}$, \\ M. Gimeno-Perezc , A. Povedad, R. Gandolfie, M. Fernández-Lobatoc, \\ F. Molinaria and F.J. Ploub, ${ }^{*}$
}

a Department of Food Environmental and Nutritional Science (DeFENS), University of Milan, 20133 Milan, Italy

b Instituto de Catalisis y Petroleoquimica, CSIC, 28049 Madrid, Spain

c Centro de Biologia Molecular Severo Ochoa, UAM-CSIC, 28049 Madrid, Spain

d Servicio Interdepartamental de Investigacion, UAM, 28049 Madrid, Spain

e Department of Pharmaceutical Science, University of Milan, 20133 Milan, Italy

\begin{abstract}
*Corresponding author: Francisco J. Plou, Instituto de Catalisis y Petroleoquimica, CSIC, Marie Curie 2, 28049 Madrid, Spain. Phone: +34-91-5854869. Fax: +34-91-5854760. E-mail: fplou@icp.csic.es.
\end{abstract}

\footnotetext{
1 ABSTRACT

2 Different filamentous fungi isolated from molasses and jams (kiwi and fig) were 3 screened for fructooligosaccharides (FOS) producing activity. Two strains, identified 4 as Penicilium sizovae (CK1) and Cladosporium cladosporioides ( $\left.\mathrm{CF}_{2} 15\right)$, were selected on 5 the basis of the FOS yield and kestose/nystose ratio. In both strains the activity was 6 mostly mycelium-bound. Starting from $600 \mathrm{~g} / \mathrm{L}$ of sucrose, maximum FOS yield was 7184 and $339 \mathrm{~g} / \mathrm{L}$ for P. sizovae and C. cladosporioides, respectively. Interestingly, the 8 highest FOS concentration with $C$. cladosporioides was reached at $93 \%$ sucrose 9 conversion, which indicated a notable transglycosylation to hydrolysis ratio. The 10 main FOS in the reaction mixtures were identified by HPAEC-PAD chromatography. 11 C. cladosporioides synthesized mainly 1-kestose $(158 \mathrm{~g} / \mathrm{L})$, nystose $(97 \mathrm{~g} / \mathrm{L}), 1 \mathrm{~F}-$ 12 fructosylnystose $(19 \mathrm{~g} / \mathrm{L}), 6$-kestose $(12 \mathrm{~g} / \mathrm{L})$, neokestose $(10 \mathrm{~g} / \mathrm{L})$ and a disaccharide
} 
(34 g/L) that after its purification and NMR analysis was identified as blastose [Fru$\beta(2 \rightarrow 6)$-Glc]. P. sizovae was very selective for the formation of ${ }^{1}$ F-FOS (in particular 1kestose) with minor contribution of neoFOS and negligible of levan-type FOS.

Key words: Fructooligosaccharides; transfructosylation; prebiotics; bioactive oligosaccharides; blastose;

\section{INTRODUCTION}

Inulin-type fructooligosaccharides (1F-FOS) are fructose oligomers with a terminal glucose unit in which 2-4 fructofuranosyl moieties are linked by $\beta(2 \rightarrow 1)$ bonds $[1 ; 2]$. ${ }^{1}$ F-FOS are used as food ingredients due to their properties, such as prebiotic action favouring the development of bifidobacteria and lactobacillus, low caloric intake $(2 \mathrm{kcal} / \mathrm{g})$, low glycemic index, improved gut absorption of $\mathrm{Ca}^{2+}$ and $\mathrm{Mg}^{2+}$, lowering of blood lipid levels, prevention of urogenital infections and reduced risk of colon cancer [3;4].

${ }^{1} \mathrm{~F}-\mathrm{FOS}$ are commonly obtained by controlled hydrolysis of inulin or other fructans (typically using inulinases, EC 3.2.1.7) [5] or by enzymatic transfructosylation of sucrose catalyzed by $\beta$-fructofuranosidases (EC 3.2.1.6) or fructosyltransferases (EC 2.4.1.9) [6]. Short-chain ${ }^{1} \mathrm{~F}-\mathrm{FOS}$ (1-kestose, nystose, $1^{\mathrm{F}}$ fructosylnystose, and so on) are currently produced at multi-ton scale from concentrated sucrose solutions using fungal transfructosylating enzymes from Aspergillus niger, Aspergillus oryzae or Aureobasidium pullulans [7;8].

Other FOS containing $\beta(2 \rightarrow 6)$ linkages between two fructose units ( ${ }^{6} \mathrm{~F}-\mathrm{FOS}$, also called levan-type FOS, such as 6-kestose or 6-nystose) [9-12] or between a fructose and a glucose ( ${ }^{6} \mathrm{G}-\mathrm{FOS}$, also called neoFOS, such as neokestose or neonystose) have also been described and are commonly produced by enzymes from yeasts [13-15]. Levan-type FOS and neoFOS are reported to exhibit improved prebiotic properties and chemical stability compared to inulin-type FOS [16-18], although more studies are required to elucidate the bioactivity of the different FOS series.

Industrial scale production of FOS is commonly performed by either soluble enzymes in batch reactions [19] or by entrapped cells in alginate gel beads using continuous fixed-bed reactors [20;21]. Several immobilized enzymes for FOS synthesis have been also developed [6;22-24]. The use of biomass (e.g. mycelia) or immobilized biocatalysts minimizes the loss of activity during operation and allows establishing a continuous process.

The identification of novel microbial strains with high transfructosylation activity and/or producing a distinctive FOS pattern is currently being investigated [25]. In this work, we have screened different microorganisms able to grow on sucrose-rich substrates such as molasses or jams with the aim of identifying new transfructosylating enzymes able to produce FOS with different composition compared with already known biocatalysts. 


\section{MATERIALS AND METHODS}

Sucrose, glucose, fructose and $p$-anisaldehyde were from Sigma-Aldrich.

Nystose and 1-kestose were from Fluka. 1F-fructosylnystose was from Megazyme. 6-

Kestose, neokestose and neonystose were synthesized as previously described [9;13;14]. Yeast extract was from Difco and barley malt flour from Diagermal. All other reagents and solvents were of the highest available purity and used as purchased.

\subsection{Isolation and screening of microorganisms with transfructosylating activity}

The fungal cultures employed in the study were isolated from molasses or from commercial and home-made kiwi and fig jams. The contents of each sample were uniformly mixed, and a sample $(1.0 \mathrm{~mL})$ was aseptically withdrawn, mixed with 9.0 $\mathrm{ml}$ of sterile water, and then diluted for isolation purposes. The inoculum was transferred to Potato Dextrose Agar (PDA) plates containing chloramphenicol $(0.05$ $\mathrm{g} / \mathrm{L})$ to inhibit bacterial growth. Plates were repeatedly incubated at $28^{\circ} \mathrm{C}$ until obtaining homogenous morphological colonies. Identification of the best performing strains was carried out at CBS (Centraal Bureau voor Schimmelcultures, Baarn, Holland) using standard molecular techniques. The microorganisms were routinely maintained on MYA slants (Barley malt flour $100 \mathrm{~g} / \mathrm{L}$, yeast extract $5 \mathrm{~g} / \mathrm{L}$, agar 15 $\mathrm{g} / \mathrm{L}, \mathrm{pH} 5.5)$ at $4^{\circ} \mathrm{C}$.

The screening for FOS production was performed by inoculating the strains into $1 \mathrm{~L}$ flasks containing $100 \mathrm{~mL}$ of liquid MY medium (Barley malt flour $100 \mathrm{~g} / \mathrm{L}$, yeast extract $5 \mathrm{~g} / \mathrm{L}, \mathrm{pH} 5.5$ ) containing $200 \mathrm{~g} / \mathrm{L}$ of sucrose. The growth was carried out on a reciprocal shaker $(150 \mathrm{rpm})$ at $28^{\circ} \mathrm{C}$. Sugar composition was analyzed by HPLC during the growth after filtration of the mycelium.

\subsection{Biotransformations with Cladosporium cladosporioides and Penicillium}

\section{sizovae}

Studies were carried out with mycelium obtained after growth on MY medium for different times (with and without $200 \mathrm{~g} / \mathrm{L}$ sucrose) under the conditions described above. Mycelia with the highest activity were found when cultures were grown on MY medium in absence of sucrose after $96 \mathrm{~h}$ on a reciprocal shaker (150 $\mathrm{rpm}$ ) at $28^{\circ} \mathrm{C}$. After centrifugation, cells were washed with sodium acetate buffer (20 $\mathrm{mM}, \mathrm{pH}$ 6.0), lyophilized and used for biotransformations.

The activity of mycelium-bound and extracellular enzymes was independently assayed [26]. Experiments with mycelium-free supernatant were accomplished using the liquid fraction obtained after centrifugation of the whole culture and ultrafiltration using a stirred ultrafiltration cell (Model 8050 Amicon, Millipore, capacity $50 \mathrm{~mL}$ ) with a $10 \mathrm{kDa}$ cut-off membrane. The extracellular fraction 
containing $0.41 \mathrm{~g} / \mathrm{L}$ of total protein (Bradford assay) was used for biotransformation, started by incubating the mixture at $50^{\circ} \mathrm{C}$ in an orbital shaker at $90 \mathrm{rpm}$ after addition of $200 \mathrm{~g} / \mathrm{L}$ of sucrose. Freshly suspended (40 g dry weight/L) and lyophilized mycelium (40 g/L) were added to 200-600 g/L sucrose solutions in 20 $\mathrm{mM}$ sodium acetate $(\mathrm{pH}$ 6.0) in a total reaction volume of $2 \mathrm{~mL}$. The mixtures were incubated at $50^{\circ} \mathrm{C}$ in an orbital shaker at $90 \mathrm{rpm}$. At different times, aliquots $(50 \mu \mathrm{L})$ were withdrawn, diluted with $200 \mu \mathrm{L}$ of water, incubated for $10 \mathrm{~min}$ at $90^{\circ} \mathrm{C}$ to inactivate the enzymes, and analyzed by HPLC to determine the total FOS yield and by HPAEC-PAD to identify the synthesized FOS.

\subsection{HPLC analysis}

The screening of transfructosylation activity and the measurement of the FOS production were carried out analyzing the corresponding reaction mixtures using hydrophilic interaction chromatography (HPLC-HILIC) with a Delta 600 quaternary pump (Waters). The chromatographic column used was a 5- $\mu$ m Luna- $\mathrm{NH}_{2} 100 \mathrm{~A}(4.6$ $\times 250 \mathrm{~mm}$ ) from Phenomenex and the HPLC detector was a refraction index 2410 from Waters. The mobile phase was acetonitrile/water $78 / 22(\mathrm{v} / \mathrm{v})$ at $1 \mathrm{~mL} / \mathrm{min}$. The temperature of the column was set at $30^{\circ} \mathrm{C}$.

\subsection{Analysis of FOS by HPAEC-PAD}

Analysis of FOS composition was carried out by high-performance anionexchange chromatography coupled with pulsed amperometric detection (HPAECPAD) on a Dionex ICS3000 system consisting of an SP gradient pump, an electrochemical detector with a gold working electrode and $\mathrm{Ag} / \mathrm{AgCl}$ as reference electrode, and an autosampler (model AS-HV). All eluents were degassed by flushing with helium. A pellicular anion-exchange $4 \times 250 \mathrm{~mm}$ Carbo-Pack PA-1 column (Dionex) connected to a $4 \times 50 \mathrm{~mm}$ CarboPac PA-1 guard column was used at $30^{\circ} \mathrm{C}$. Eluent preparation was performed with Milli-Q water and $\mathrm{NaOH}$. The initial mobile phase (at $0.5 \mathrm{~mL} / \mathrm{min}$ ) was $100 \mathrm{mM} \mathrm{NaOH}$. A gradient from 0 to 200 $\mathrm{mM}$ sodium acetate was performed in $50 \mathrm{~min}$ at $0.5 \mathrm{~mL} / \mathrm{min}$, and $200 \mathrm{mM}$ sodium acetate was maintained for $25 \mathrm{~min}$. The chromatograms were analyzed using Chromeleon software. The identification of the different carbohydrates was done on the basis of standards commercially available or purified in our laboratory.

\subsection{Isolation of an unknown carbohydrate}

The biocatalytic reaction with the $C$. cladosporioides $\mathrm{CF}_{2} 15$ enzymatic preparation was scaled up to $10 \mathrm{~mL}$. At the point of maximum concentration of the unknown oligosaccharide, the reaction was stopped by inactivation at $100^{\circ} \mathrm{C}(10 \mathrm{~min})$ followed by filtration. The mixture was purified by semi-preparative HPLC using a system equipped with a Waters Delta 600 pump coupled to a $5 \mu \mathrm{m}$ Kromasil- $\mathrm{NH}_{2}$ column (10 x 250 mm; Analisis Vinicos). A three-way flow splitter (model Accurate, Dionex) and a refraction index detector (Waters, model 2410 ) equilibrated at $30^{\circ} \mathrm{C}$ were used. 
1 Acetonitrile/water 70:30 (v/v), degassed with helium, was used as mobile phase at

$24.7 \mathrm{~mL} / \mathrm{min}$ for $40 \mathrm{~min}$. The column temperature was kept constant at $30^{\circ} \mathrm{C}$. After

3 collecting the different oligosaccharides, the mobile phase was eliminated by rotary

4 evaporation in a R-210 rotavapor (Buchi).

\subsection{Mass Spectrometry}

The unknown carbohydrate was analyzed by MALDI-TOF mass spectrometry 7 (Bruker, model Ultraflex III TOF-TOF) using 2,5-dihydroxybenzoic acid doped with

$8 \mathrm{NaI}$ as matrix, in positive reflector mode.

\subsection{Nuclear Magnetic Resonance (NMR)}

The structure of the unknown carbohydrate was elucidated using a combination of $1 \mathrm{H}, 13 \mathrm{C}$ and 2D-NMR (COSY, TOCSY, NOESY, HSQC, HMBC)

12 techniques. The spectra of the sample (ca. $10 \mathrm{mM}$ ), dissolved in deuterated water, 13 was recorded on a Bruker AVANCE DRX500 spectrometer equipped with a tuneable 14 broadband $1 \mathrm{H} / \mathrm{X}$ probe with a gradient in the $\mathrm{Z}$ axis, at a temperature of $298 \mathrm{~K}$.

15 Chemical shifts were expressed in ppm with respect to the 0 ppm point of DSS, used 16 as internal standard. COSY, NOESY, HSQC, HSQC-TOCSY, DEPT-HSQC and

17 HMBC sequences were provided by Bruker. COSY, TOCSY ( $80 \mathrm{~ms}$ mixing time), and 18 NOESY (500 ms mixing time) experiments were performed with 8, 32, and 64 scans, 19 respectively, with 256 increments in the indirect dimension and with 1024 points in 20 the acquisition dimension. The spectral widths were $5 \mathrm{ppm}$ in both dimensions. The 21 HSQC and related experiments (16 scans) also used 256 increments in the indirect 22 dimension and 1024 points in the acquisition dimension. The HMBC (64 scans) used 23384 increments in the indirect dimension and 1024 points in the acquisition

24 dimension. The spectral width for the heteronuclear correlations was $120 \mathrm{ppm}$ in the indirect dimension and $5 \mathrm{ppm}$ in the acquisition one. 


\section{RESULTS AND DISCUSSION}

\subsection{Screening of transfructosylation activity}

Filamentous fungi (45 strains), isolated from sucrose-rich environments (jams and molasses), were firstly grown on a MY medium (see Experimental Section) containing $200 \mathrm{~g} / \mathrm{L}$ sucrose, and FOS production was followed during the growth. The carbohydrate composition of the supernatant was analyzed by HPLC-HILIC, showing that 14 strains (Table 1) were able to produce FOS in different concentration (referred to the total amount of sugars in the sample) and composition (indicated in the table by the kestose/nystose ratio, $\mathrm{K} / \mathrm{N})$. Two strains $\left(\mathrm{CF}_{2} 15\right.$ and $\mathrm{CK} 1$, identified as Cladosporium cladosporioides and Penicillium sizovae, respectively) gave maximum FOS production in shorter times $(48 \mathrm{~h})$ and were selected for their ability to synthesize FOS with different $\mathrm{K} / \mathrm{N}$ ratios (0.8 and 6.0, respectively), at the point of maximum FOS concentration. Notably, Cladosporium cladosporioides gave the highest production of total FOS, whereas Penicillium sizovae was very selective, furnishing kestose as the main product.

\subsection{Total FOS production with lyophilized mycelium of C. cladosporioides and}

\section{P. sizovae}

The extracellular and cell-bound transfructosylating activity of $P$. sizovae and $C$. cladosporioides to produce FOS was evaluated using cultures grown on liquid MY medium. Cell-free supernatant (broth fraction) and washed mycelium were independently assayed to locate the transfructosylating activity. The supernatant gave conversions into total FOS lower than $5 \%$ for both strains, showing that the activity was mostly mycelium-bound. No significant differences were observed in the activity of mycelium grown in the medium with or without sucrose. Therefore, mycelium of cultures grown in liquid MY medium without sucrose was used for further experiments aimed at optimization and product characterization. Mycelia did not lose any significant activity upon lyophilisation (data not shown). It is well reported that lyophilized mycelia of fungi are easy-to-handle biocatalysts often showing remarkable long-term stability $[27,28]$. Lyophilized mycelia of the two strains were used for FOS production using various initial sucrose concentrations (200-600 g/L), and the highest yields of total FOS were obtained with $600 \mathrm{~g} / \mathrm{L}$ of sucrose (Table 2).

The time course of total FOS formation with P. sizovae and C. cladosporioides using $600 \mathrm{~g} / \mathrm{L}$ sucrose was followed by HPLC-HILIC and is represented in Figs. 1A and $1 \mathrm{~B}$, respectively. P. sizovae mycelium produced $184 \mathrm{~g} / \mathrm{L}$ of total FOS $(31 \% \mathrm{w} / \mathrm{w}$ of total sugars, after $24 \mathrm{~h}$ ), which was obtained at $53 \%$ sucrose conversion, whereas C. cladosporioides mycelium synthesized $339 \mathrm{~g} / \mathrm{L}$ of FOS (56\% w/w, after $72 \mathrm{~h})$ at $93 \%$ sucrose conversion. The fact that maximum FOS concentration with $C$. cladosporioides 
enzyme was obtained when only $7 \%$ of initial sucrose remains in the mixture indicates that the transglycosylation to hydrolysis ratio of this enzyme is notable [29]. The yield of total FOS obtained with C. cladosporioides is close to the maximum values reported (around 60\%) for the industrial processes with Aspergillus or Aureobasidium sp. enzymes [29-31].

\subsection{Characterization of synthesized FOS}

HPAEC-PAD was employed for the characterization of the FOS synthesized in the reactions with $P$. sizovae and C. cladosporioides using $600 \mathrm{~g} / \mathrm{L}$ sucrose. According to the chromatograms presented in Figure 2, we detected at least 13 different carbohydrates in the reactions mediated by P. sizovae (Fig. 2A) and C. cladosporioides (Fig. 2B) mycelia. Peaks 1, 2, and 3 corresponded to glucose, fructose and sucrose, respectively. As illustrated in the chromatogram $2 \mathrm{~B}$, the main products present in the reaction mixture with $C$. cladosporioides were peaks 4 (1-kestose) and 9 (nystose). Peaks 7,8 and 10 were identified as 6-kestose, neokestose and neonystose, respectively, using standards previously purified in our laboratory as described [9;13]. Peak 12 was the pentasaccharide ${ }^{1}$ F-fructosylnystose. The oligosaccharides corresponding to peaks 6,11 and 13 could not be identified so far. Figure 3 illustrates the structures of the different carbohydrates obtained in these reactions.

The compound corresponding to peak 5 was purified by semi-preparative HPLC. Its mass spectrum showed that it was a disaccharide. The $1 \mathrm{D}$ and $2 \mathrm{D}{ }^{1} \mathrm{H}$ NMR spectra displayed two anomeric signals, arising from the typical $\alpha / \beta$ equilibrium and a signal pattern recognizable as fructose and glucose residues. From the combination of the signals from COSY, TOCSY, NOESY, HSQC and HMBC spectra, full assignment of the ${ }^{1} \mathrm{H}$ and ${ }^{13} \mathrm{C}$ resonance signals belonging to the different residues was achieved. The glycosylation position was determined from the existence of a crosspeak between the $\mathrm{H} 6$ from glucose and the quaternary carbon $\mathrm{C} 2$ from fructose in the HMBC spectrum. The NMR data unequivocally permitted to identify the compound as blastose [Fru- $\beta(2 \rightarrow 6)-G l c]$ (Figure 4$)$, a sucrose isomer member of the neoFOS series. Despite it is a non-conventional disaccharide, the isolation and chemical characterization of blastose was first described in submerged cultures and honeydew of Claviceps africana and Clavices shorgi [32]. Besides forming polyfructans, the levansucrase from Bacillus megaterium also synthesized five different oligosaccharides including blastose [33].

\subsection{Production of the different FOS}

The FOS formation was analyzed in detail using HPAEC-PAD. Figure 5 illustrates the profile of the biotransformation with lyophilized mycelium of $C$. cladosporioides starting from $600 \mathrm{~g} / \mathrm{L}$ of sucrose. At the point of maximum FOS concentration $(72 \mathrm{~h})$, the FOS fraction was mainly composed of 1-kestose (158 g/L) and nystose $(97 \mathrm{~g} / \mathrm{L})$, with formation of lower amounts of the disaccharide blastose $(34 \mathrm{~g} / \mathrm{L}),{ }^{1}$-fructosylnystose $(19 \mathrm{~g} / \mathrm{L}), 6$-kestose $(12 \mathrm{~g} / \mathrm{L})$ and neokestose $(10 \mathrm{~g} / \mathrm{L})$. Neonystose was only slightly detected at the end of the reaction $(96 \mathrm{~h})$. The yield of 
1F-FOS obtained with C. cladosporioides (approx. 46\%) was lower than the reported with Aspergillus niger, Aspergillus japonicus, Aureobasidium pullulans or Penicillium expansum (60-66\%) [34]. However, the mixture of ${ }^{1} \mathrm{~F}-\mathrm{FOS},{ }^{6} \mathrm{~F}-\mathrm{FOS}$ and ${ }^{6} \mathrm{G}-\mathrm{FOS}$ synthesized by C. cladosporioides could display a synergistic effect; a similar FOS

\section{Acknowledgements}

38 Projects BIO2010-20508-C04-01, BIO2010-20508-C04-04, BIO2013-48779-C4-1-R and composition enclosing products of the three families was also described with the $\beta$ fructofuranosidase from Rhodotorula dairenensis [35].

The concentration of neokestose never surpassed $10 \mathrm{~g} / \mathrm{L}$ throughout the reaction; however, blastose concentration was significantly higher $(>30 \mathrm{~g} / \mathrm{L})$ after $48 \mathrm{~h}$. This result suggests that blastose is not formed by hydrolysis of neokestose, but by the transfer of fructosyl moiety to the released glucose in the medium. In fact, the biosynthetic activity detected in the $C$. cladosporioides mycelium is not very efficient to hydrolyze the $\beta(2 \rightarrow 6)$ linkages between a fructose and a glucose, as the neoFOS concentration is not diminishing throughout the process, in contrast with ${ }^{1} \mathrm{~F}-\mathrm{FOS}$ (Fig. 5).

Figure 6 shows the formation of the different FOS with lyophilized mycelium of P. sizovae. At the point of maximum FOS yield $(24 \mathrm{~h}), 156 \mathrm{~g} / \mathrm{L}$ out of the total FOS concentration (184 g/L) corresponded to 1-kestose. The FOS fraction was completed with nystose $(11 \mathrm{~g} / \mathrm{L})$, neokestose $(6 \mathrm{~g} / \mathrm{L})$ and neonystose $(11 \mathrm{~g} / \mathrm{L})$. The $P$. sizovae enzyme displays a more typical profile with major formation of ${ }^{1} \mathrm{~F}-\mathrm{FOS}$, which represented a yield of $28 \%$. However, its transglycosylation to hydrolysis ratio is less favourable than that of $C$. cladosporioides. It is interesting to note the negligible presence of blastose with the $P$. sizovae enzyme, which indicates its much lower tendency to use glucose as acceptor to form $\beta(2 \rightarrow 6)$ linkages.

\section{CONCLUSION}

The main enzymes used for industrial production of FOS generally provide a mixture of molecules with the inulin-type structure, ${ }^{1} \mathrm{~F}-\mathrm{FOS}$, whereas those from yeasts usually form levan-type FOS ( $\left.{ }^{6} \mathrm{~F}-\mathrm{FOS}\right)$ or neoFOS ( $\left.{ }^{6} \mathrm{G}-\mathrm{FOS}\right)$. In this work, two filamentous fungi (Cladosporium cladosporioides and Penicilium sizovae) showing mycelium-bound transfructosylating activity were isolated. Maximum FOS yields were $56 \%$ and $31 \%$ for C. cladosporioides and P. sizovae respectively. Interestingly, C. cladosporioides synthesized a mixture of ${ }^{1} \mathrm{~F}-\mathrm{FOS},{ }^{6} \mathrm{~F}-\mathrm{FOS}$ and ${ }^{6} \mathrm{G}-\mathrm{FOS}$, including the presence of a non-conventional disaccharide (blastose). Considering that the FOS yield with $C$. cladosporioides is close to that obtained with typical Aspergillus or Aureobasidium enzymes, the formation of a mixture of FOS with different glycosidic linkages could give rise to certain benefits regarding their bioactivity. BIO2013-48779-C4-4-R from Spanish Ministry of Economy and Competitiveness supported this research. We thank Lifelong Learning Programme/Erasmus student placement 2012/2013, and Fundacion Ramon Areces for the institutional Grant to the Centro de Biología Molecular Severo Ochoa. 


\section{Reference List}

[1] Antosova M, Polakovic M. Fructosyltransferases: The enzymes catalyzing production of fructooligosaccharides. Chem Pap-Chem Zvesti 2001;55:350-358.

[2] Kelly G. Inulin-type prebiotics - A review: Part 1. Altern Med Rev 2008;13:315329.

[3] Huebner J, Wehling RL, Hutkins RW. Functional activity of commercial prebiotics. Int. Dairy J 2007;17:770-775.

[4] Scholz-Ahrens KE, Ade P, Marten B, Weber P, Timm W, Asil Y, Gluer CC, Schrezenmeir J. Prebiotics, probiotics, and synbiotics affect mineral absorption, bone mineral content, and bone structure. J Nutr 2007;137:838S-846S.

[5] Nguyen QD, Rezessy-Szabo JM, Czukor B, Hoschke A. Continuous production of oligofructose syrup from Jerusalem artichoke juice by immobilized endo-inulinase. Process Biochem 2011;46:298-303.

[6] Kurakake M, Masumoto RYO, Maguma K, Kamata A, Saito E, Ukita N, Komaki T. Production of fructooligosaccharides by $\beta$-fructofuranosidases from Aspergillus oryzae KB. J Agric Food Chem 2010;58:488-492.

[7] Sangeetha PT, Ramesh MN, Prapulla SG. Fructooligosaccharide production using fructosyl transferase obtained from recycling culture of Aspergillus oryzae CFR 202. Process Biochem 2005;40:1085-1088.

[8] Plou FJ, Martin MT, Gomez de Segura A, Alcalde M, Ballesteros A. Glucosyltransferases acting on starch or sucrose for the synthesis of oligosaccharides. Can J Chem 2002;80:743-752.

[9] Alvaro-Benito M, de Abreu M, Fernandez-Arrojo L, Plou FJ, Jimenez-Barbero J, Ballesteros A, Polaina J, Fernandez-Lobato M. Characterization of a $\beta$ fructofuranosidase from Schwanniomyces occidentalis with transfructosylating activity yielding the prebiotic 6-kestose. J Biotechnol 2007;132:75-81. 
[10] Alvaro-Benito M, Sainz-Polo MA, Gonzalez-Perez D, Gonzalez B, Plou FJ, Fernandez-Lobato M, Sanz-Aparicio J. Structural and kinetic insights reveal that the amino acid pair Gln-228/ Asn-254 modulates the transfructosylating specificity of Schwanniomyces occidentalis $\beta$-fructofuranosidase, an enzyme that produces prebiotics. J Biol Chem 2012;287:19674-19686.

[11] de Abreu M, Alvaro-Benito M, Plou FJ, Fernandez-Lobato M, Alcalde M. Screening $\beta$-fructofuranosidases mutant libraries to enhance the transglycosylation yield of $\beta$-(2-6) fructooligosacharides. Comb Chem High T Scr 2011;14:730-738.

[12] De Abreu M, Alvaro-Benito M, Sanz-Aparicio J, Plou FJ, Fernandez-Lobato M, Alcalde M. Synthesis of 6-kestose using an efficient beta-fructofuranosidase engineered by directed evolution. Adv Synth Catal 2013;355:1698-1702.

[13] Linde D, Macias I, Fernandez-Arrojo L, Plou FJ, Fernandez-Lobato M. Molecular and biochemical characterization of a $\beta$-fructofuranosidase from Xanthophyllomyces dendrorhous. Appl Environ Microbiol 2009;75:1065-1073.

[14] Linde D, Rodriguez-Colinas B, Estevez M, Poveda A, Plou FJ, Fernandez-Lobato M. Analysis of neofructooligosaccharides production mediated by the extracellular $\beta$-fructofuranosidase from Xanthophyllomyces dendrorhous. Bioresour Technol 2012;109:123-130.

[15] Lafraya A, Sanz-Aparicio J, Polaina J, Marin-Navarro J. Fructo-oligosaccharide synthesis by mutant versions of Saccharomyces cerevisiae invertase. Appl Environ Microbiol 2011;77:6148-6157.

[16] Hayashi S, Yoshiyama T, Fujii N, Shinohara S. Production of a novel syrup containing neofructo-oligosaccharides by the cells of Penicillium citrinum. Biotechnol Lett 2000;22:1465-1469. 
[17] Kilian S, Kritzinger S, Rycroft C, Gibson G, du Preez J. The effects of the novel bifidogenic trisaccharide, neokestose, on the human colonic microbiota. World J Microb Biot 2002;18:637-644.

[18] Lim JS, Lee JH, Kang SW, Park SW, Kim SW. Studies on production and physical properties of neo-FOS produced by co-immobilized Penicillium citrinum and neofructosyltransferase. Eur Food Res Technol 2007;225:457-462.

[19] Hidaka H, Eida T, Adachi T, Saitoh Y. Industrial-production of fructooligosaccharides and its application for human and animals. J Jpn Soc Food Sci 1987;61:915-923.

[20] Yun JW, Kang SC, Song SK. Continuous production of fructooligosaccharides from sucrose by immobilized fructosyltransferase. Biotechnol Tech 1995;9:805808.

[21] Park MC, Lim JS, Kim JC, Park SW, Kim SW. Continuous production of neofructooligosaccharides by immobilization of whole cells of Penicillium citrinum. Biotechnol Lett 2005;27:127-130.

[22] Smaali I, Soussi A, Bouallagui H, Chaira N, Hamdi M, Marzouki MN. Production of high-fructose syrup from date by-products in a packed bed bioreactor using a novel thermostable invertase from Aspergillus awamori. Biocatal Biotransfor 2011;29:253-261.

[23] Fernandez-Arrojo L, Rodriguez-Colinas B, Gutierrez-Alonso P, Fernandez-Lobato M, Alcalde M, Ballesteros AO, Plou FJ. Dried alginate-entrapped enzymes (DALGEEs) and their application to the production of fructooligosaccharides. Process Biochem 2013;48:677-682.

[24] Alvarado-Huallanco MB, Maugeri-Filho F. Kinetics and modeling of fructooligosaccharide synthesis by immobilized fructosyltransferase from Rhodotorula sp. J Chem Technol Biotechnol 2010;85:1654-1662. 
[25] Ganaie MA, Gupta US, Kango N. Screening of biocatalysts for transformation of sucrose to fructooligosaccharides. J Mol Catal B-Enzym 2013;97:12-17.

[26] Gandolfi R, Marinelli F, Lazzarini A, Molinari F. Cell-bound and extracellular carboxylesterases from streptomyces: hydrolytic and synthetic activities. J Appl Microbiol 2000;89:870-875.

[27] Gandolfi R, Converti A, Pirozzi D, Molinari F. Efficient and selective microbial esterification with dry mycelium of Rhizopus oryzae. J Biotechnol 2001;92:21-26

[28] Converti A, Del Borghi A, Gandolfi R Lodi A, Molinari F, Palazzi E. Reactivity and stability of mycelium-bound carboxylesterase from Aspergillus oryzae. Biotechnol Bioeng 2002;77:232-237.

[29] Plou FJ, Alcalde M, Ghazi I, Fernandez-Arrojo L., Ballesteros A. Efficient fructooligosaccharide synthesis with a fructosyltransferase from Aspergillus aculeatus. In: Fessner WD, Anthonsen T eds. Modern Biocatalysis: Stereoselective and enviromentally friendly reactions. Weinheim, Germany: Wiley-VCH; 2009. p. $153-71$.

[30] Fernandez RC, Maresma BG, Juarez A, Martinez J. Production of fructooligosaccharides by beta-fructofuranosidase from Aspergillus sp 27H. J Chem Technol Biotechnol 2004;79:268-272.

[31] Sangeetha PT, Ramesh MN, Prapulla SG. Production of fructo-oligosaccharides by fructosyl transferase from Aspergillus oryzae CFR 202 and Aureobasidium pullulans CFR 77. Process Biochem 2004;39:753-758.

[32] Flieger M, Kantorova M, Halada P, Kuzma M, Pazoutova S, Stodulkova E, Kolinska R. Oligosaccharides produced by submerged cultures of Claviceps africana and Claviceps sorghi. Folia Microbiol 2005;50:198-204

[33] Homann A, Biedendieck R, Gotze S, Jahn D, Seibel J. Insights into polymer versus oligosaccharide synthesis: mutagenesis and mechanistic studies of a novel levansucrase from Bacillus megaterium. Biochem J 2007;407:189-198. 
1 [34] Ortiz-Soto ME, Seibel J. Biotechnological synthesis and transformation of valuable sugars in the food and pharmaceutical industry. Curr Org Chem 2014;18:964-986.

4 [35] Gutierrez-Alonso P, Fernandez-Arrojo L, Plou FJ, Fernandez-Lobato M. Biochemical characterization of a $\beta$-fructofuranosidase from Rhodotorula dairenensis with transfructosylating activity. FEMS Yeast Res 2009;9:768-773. 
Table 1. Initial screening of FOS-synthesizing microorganisms in fruit jams and molasses. Experimental conditions: biotransformations with growing cells in MY medium (including $200 \mathrm{~g} / \mathrm{L}$ sucrose), $28^{\circ} \mathrm{C}, 150 \mathrm{rpm}$. Carbohydrates: F, fructose; $\mathrm{G}$, glucose; $\mathrm{S}$, sucrose; $\mathrm{K}$, total kestoses; $\mathrm{N}$, total nystoses; FN fructosylnystose; $\mathrm{K} / \mathrm{N}$, kestose/nystose ratio.

\begin{tabular}{|c|c|c|c|c|c|c|c|c|}
\hline \multirow[t]{2}{*}{ Strain } & \multirow[t]{2}{*}{ Time (h) $)^{a}$} & \multicolumn{6}{|c|}{ Composition (\%) b } & \multirow{2}{*}{$\begin{array}{l}\mathrm{K} / \mathrm{N} \\
\text { ratio }\end{array}$} \\
\hline & & F (\%) & G (\%) & $S(\%)$ & K (\%) & $\mathbf{N}(\%)$ & FN (\%) & \\
\hline $\mathrm{CF}_{2} 3 \mathrm{~V}$ & 96 & 2 & 33 & 9 & 32 & 24 & - & 1.3 \\
\hline $\mathrm{CF}_{2} 4 \mathrm{~V}$ & 96 & 8 & 43 & 9 & 12 & 18 & 9 & 0.7 \\
\hline $\mathrm{CF}_{2} 15$ & 48 & 5 & 34 & 6 & 23 & 27 & 5 & 0.8 \\
\hline CK1 & 48 & 12 & 25 & 35 & 24 & 4 & - & 6.0 \\
\hline M1A & 96 & 4 & 30 & 13 & 36 & 17 & - & 2.1 \\
\hline $\mathrm{CF}_{1} 1$ & 72 & 2 & 18 & 50 & 21 & 9 & & 4.4 \\
\hline $\mathrm{CF}_{1} 2$ & 48 & 11 & 14 & 69 & 3 & - & - & \\
\hline $\mathrm{CF}_{2} 7$ & 96 & 3 & 12 & 67 & 13 & 7 & - & \\
\hline $\mathrm{CF}_{2} 9 \mathrm{~V}$ & 48 & 48 & 47 & 3 & 3 & - & - & - \\
\hline $\mathrm{CF}_{2} 11$ & 72 & 3 & 5 & 87 & 4 & - & - & - \\
\hline $\mathrm{CF}_{2} 12$ & 96 & 8 & 20 & 57 & 10 & 5 & - & 2.0 \\
\hline $\mathrm{CF}_{2} 14$ & 96 & 6 & 31 & 43 & 18 & 4 & - & 4.0 \\
\hline $\mathrm{CF}_{2} 16$ & 48 & 2 & 24 & 47 & 12 & 5 & - & 2.4 \\
\hline SD4 & 96 & 5 & 26 & 58 & 16 & 5 & - & 3.2 \\
\hline
\end{tabular}

a Time of maximum FOS production

${ }^{\mathrm{b}}$ Weight percentage referred to the total amount of sugars in the mixture. Standard deviations were lower than $5 \%$. 
Table 2. FOS production with lyophilized mycelium of Cladosporium cladosporioides and Penicilium sizovae using different sucrose (S) concentrations.

\begin{tabular}{|c|c|c|c|c|c|c|c|c|}
\hline \multirow[t]{2}{*}{ Strain } & \multirow{2}{*}{$\begin{array}{c}{[S]} \\
(g / L) \\
\end{array}$} & \multirow{2}{*}{$\begin{array}{l}\text { Time } \\
(\mathrm{h})^{\mathrm{a}}\end{array}$} & \multicolumn{6}{|c|}{ Composition (\%)b } \\
\hline & & & $\begin{array}{c}F \\
(\%)\end{array}$ & $\begin{array}{l}\mathrm{G} \\
(\%)\end{array}$ & $\begin{array}{c}S \\
(\%)\end{array}$ & $\begin{array}{c}\mathrm{K} \\
(\%)\end{array}$ & $\begin{array}{l}\mathrm{N} \\
(\%)\end{array}$ & $\begin{array}{l}\mathrm{FN} \\
(\%)\end{array}$ \\
\hline $\begin{array}{l}\text { C. } \\
\text { cladosporioides }\end{array}$ & 200 & 24 & 8 & 30 & 10 & 23 & 7 & 7 \\
\hline $\begin{array}{l}\text { C. } \\
\text { cladosporioides }\end{array}$ & 400 & 48 & 4 & 30 & 18 & 32 & 11 & 5 \\
\hline $\begin{array}{l}\text { C. } \\
\text { cladosporioides }\end{array}$ & 600 & 72 & 3 & 33 & 12 & 30 & 18 & 4 \\
\hline P. sizovae & 200 & 24 & 19 & 30 & 25 & 24 & 2 & - \\
\hline P. sizovae & 400 & 24 & 12 & 23 & 36 & 25 & 4 & - \\
\hline P. sizovae & 600 & 24 & 4 & 17 & 47 & 27 & 5 & - \\
\hline
\end{tabular}

a Time of maximum FOS production

$\mathrm{b}$ Weight percentage referred to the total amount of sugars in the mixture. Standard deviations were lower than $5 \%$. 


\section{Figure legends}

Figure 1. Time course of the reaction of sucrose with $P$. sizovae $(\mathbf{A})$ and $C$. cladosporioides (B) mycelia. Reaction conditions: $600 \mathrm{~g} / \mathrm{L}$ sucrose, $40 \mathrm{~g} / \mathrm{L}$ lyophilized mycelium, $20 \mathrm{mM}$ sodium acetate buffer $(\mathrm{pH} 6.0), 50^{\circ} \mathrm{C}$. Standard deviations were lower than $5 \%$.

Figure 2. HPAEC-PAD analysis of the reaction of sucrose with P. sizovae (A) and C. cladosporioides (B) mycelia at the point of maximum FOS concentration. Peaks: 1: glucose; 2: fructose; 3: sucrose; 4: 1-kestose; 5: blastose; 7: 6-Kestose; 8 : neokestose; 9: nystose; 10: neo-nystose; 12: ${ }^{1} \mathrm{~F}-$ fructosylnystose; $6,11,13$ : unknown.

Figure 3. Structure of the fructooligosaccharides produced by $P$. sizovae and $C$. cladosporioides transfructosylating activity.

Figure 4. 2D-NMR DEPT-HSQC spectra of blastose [Fru- $\beta(2 \rightarrow 6)-G l c]$. The signals are assigned and labelled. The key points for identifications are also shown.

Figure 5. Kinetics of FOS formation using $600 \mathrm{~g} / \mathrm{L}$ sucrose catalyzed by lyophilized C. cladosporioides. Reaction conditions: $40 \mathrm{~g} / \mathrm{L}$ lyophilized mycelium, $20 \mathrm{mM}$ sodium acetate buffer $(\mathrm{pH} 6.0), 50^{\circ} \mathrm{C}$. Standard deviations were lower than $5 \%$.

Figure 6. Kinetics of FOS formation using $600 \mathrm{~g} / \mathrm{L}$ sucrose catalyzed by lyophilized $P$. sizovae (40 g/L). Reaction conditions: $40 \mathrm{~g} / \mathrm{L}$ lyophilized mycelium, $20 \mathrm{mM}$ sodium acetate buffer $(\mathrm{pH} 6.0), 50^{\circ} \mathrm{C}$. Standard deviations were lower than $5 \%$. 
Fig. 1
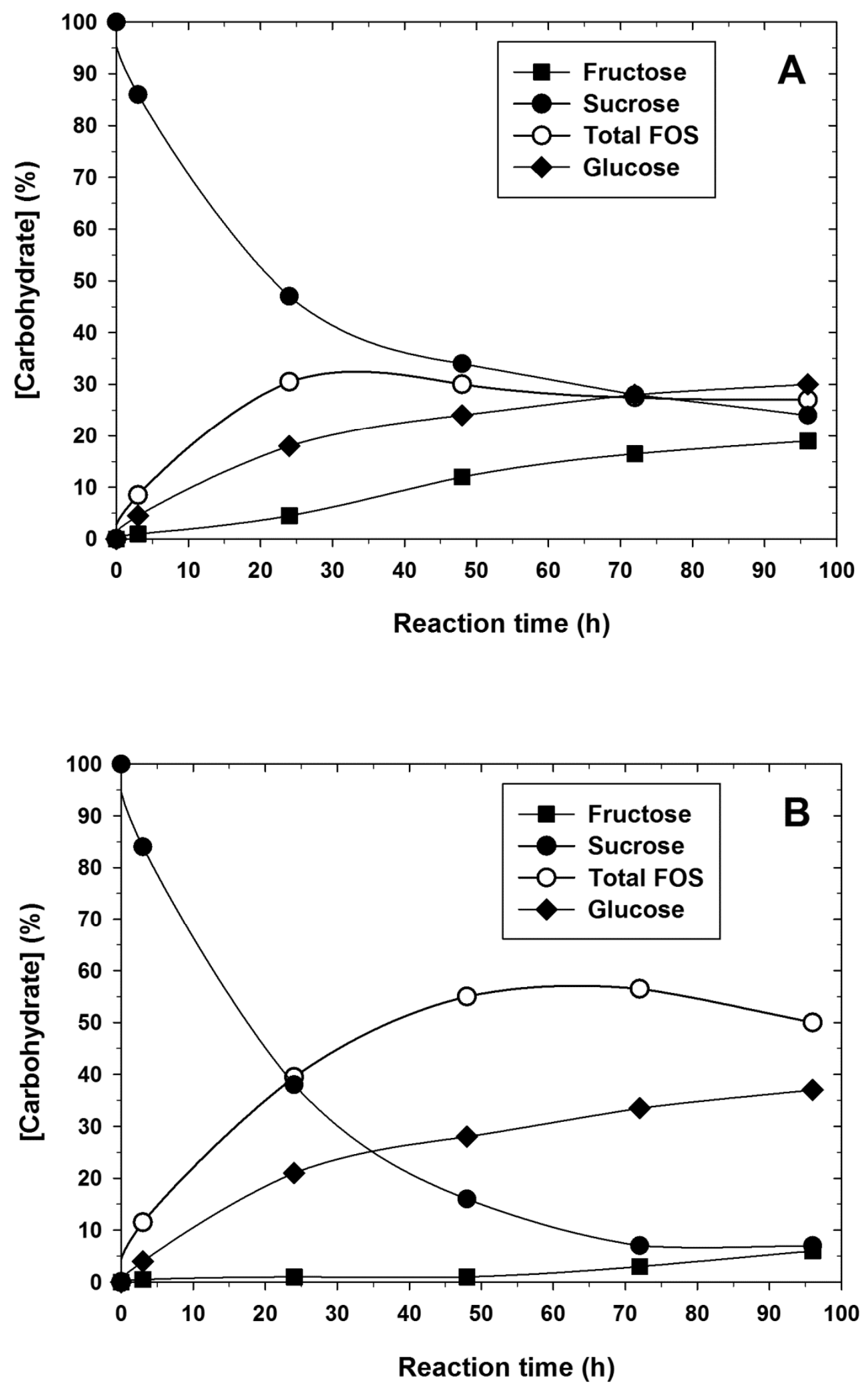
Fig. 2
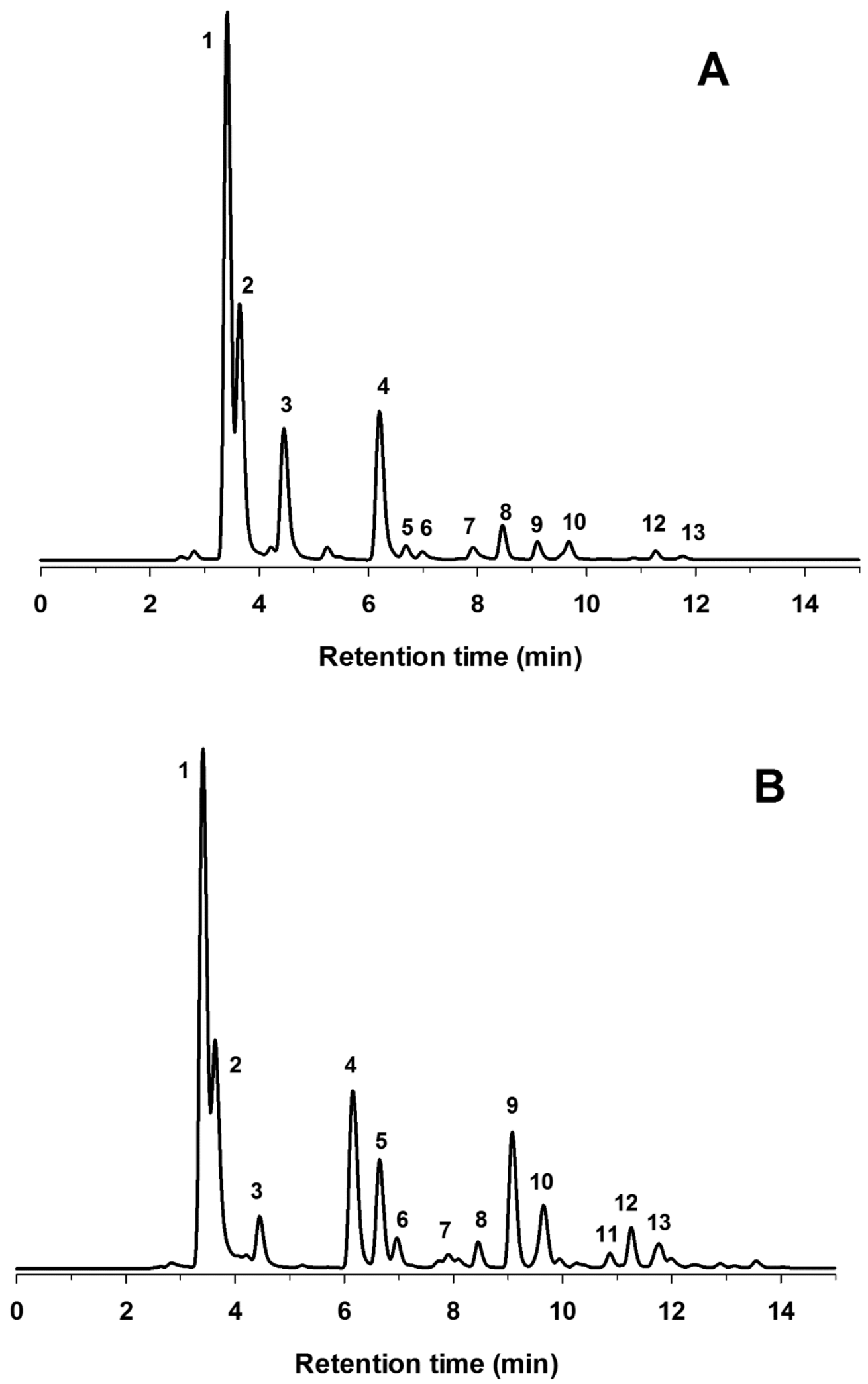
Fig. 3

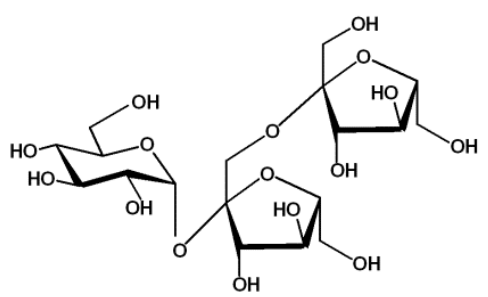

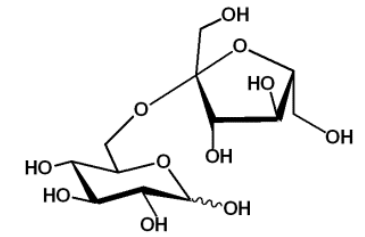

Blastose

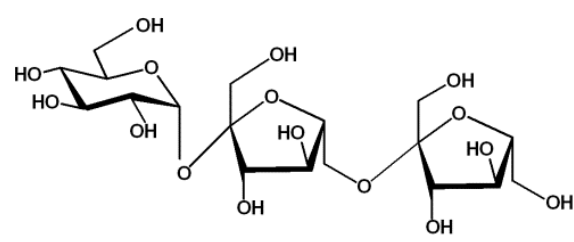

6-Kestose
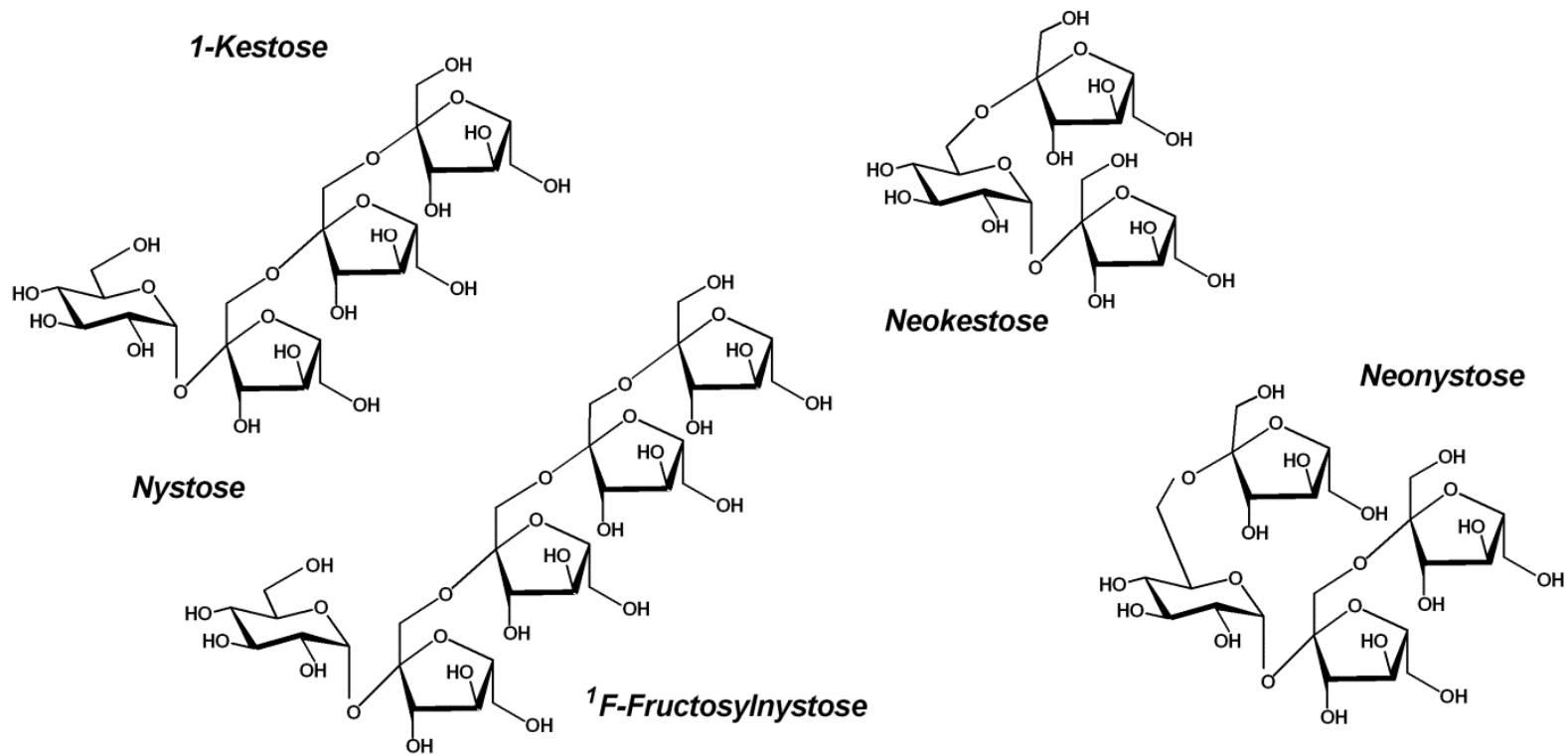
Fig. 4

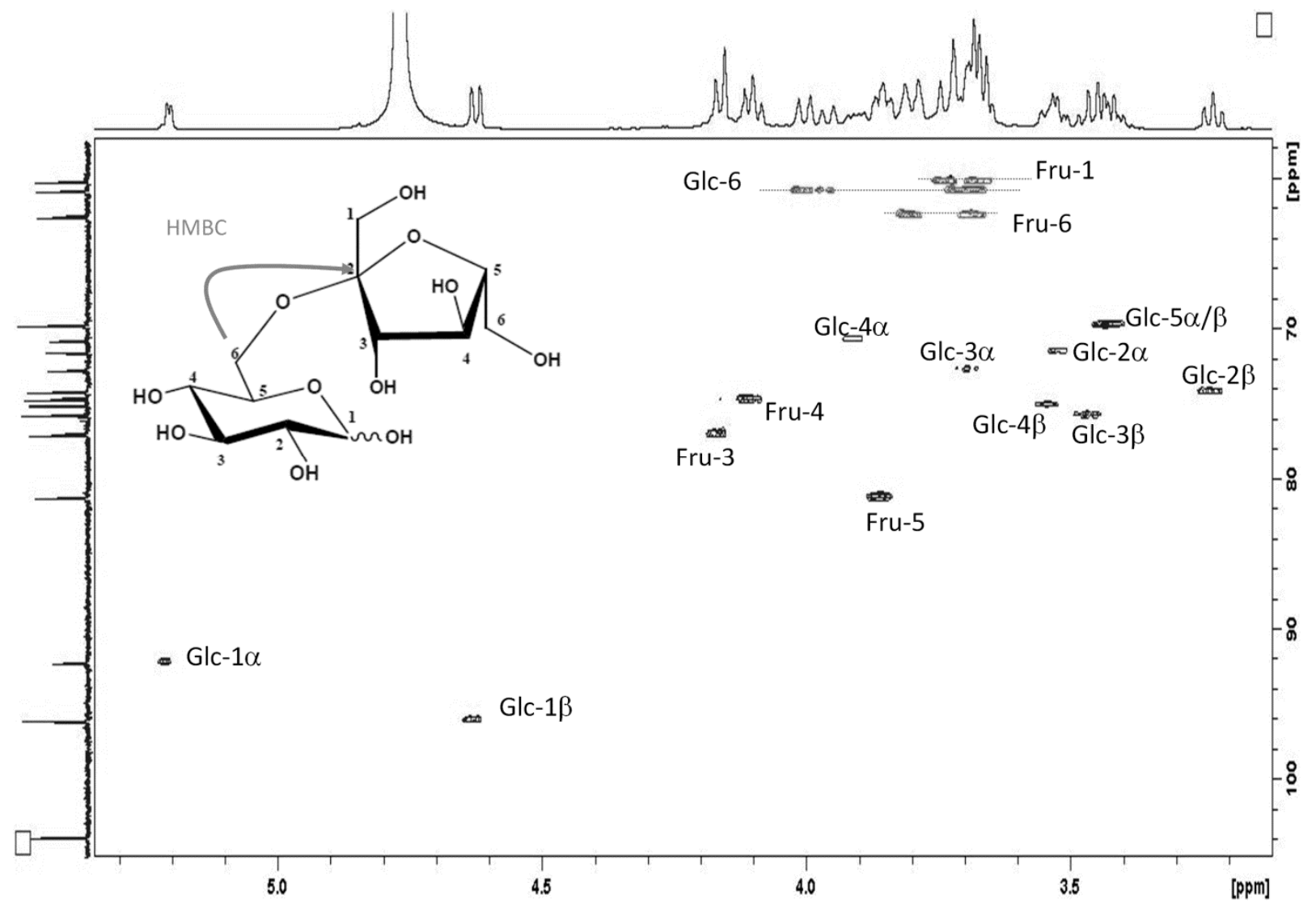


Fig. 5

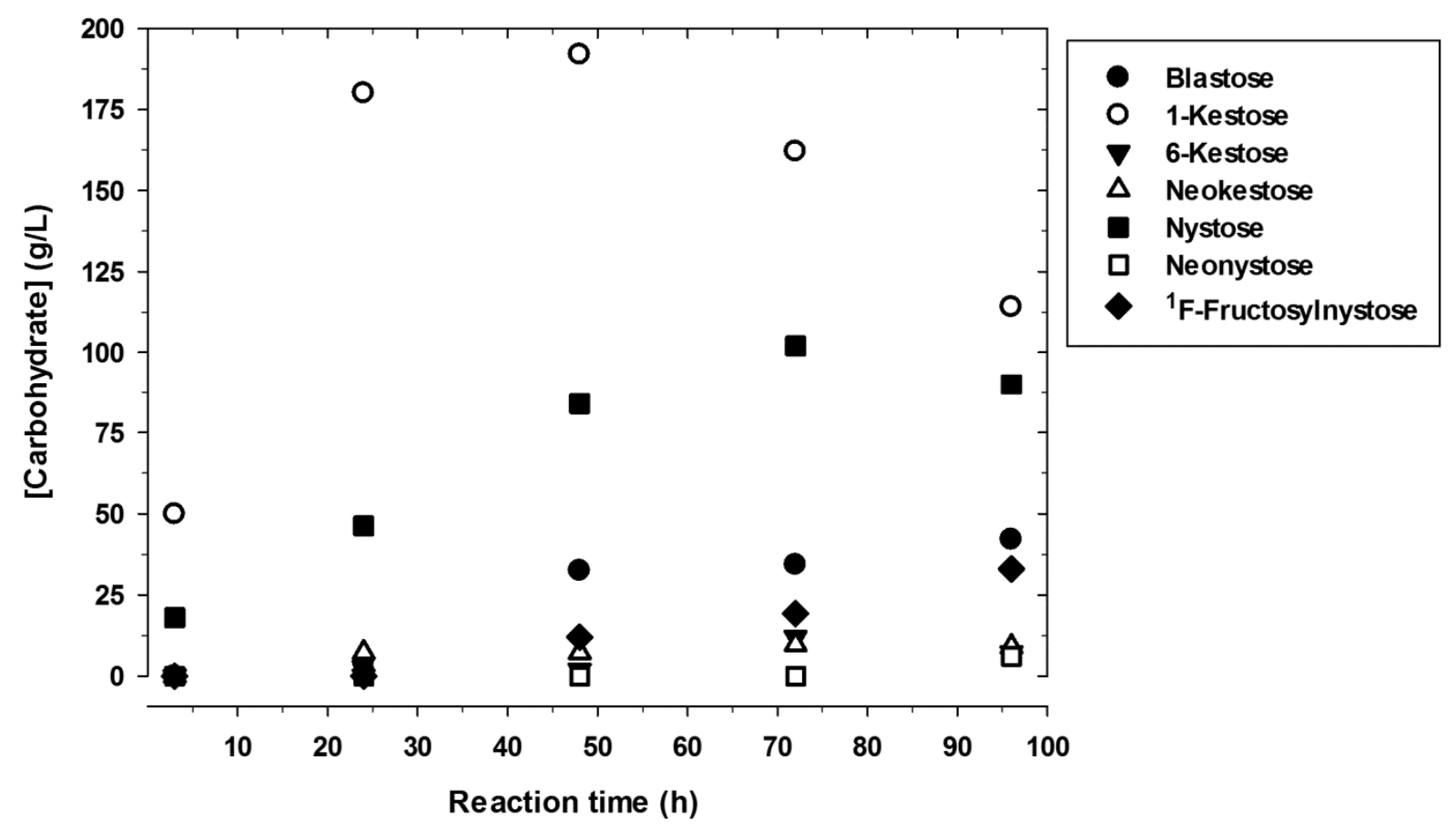


Fig. 6

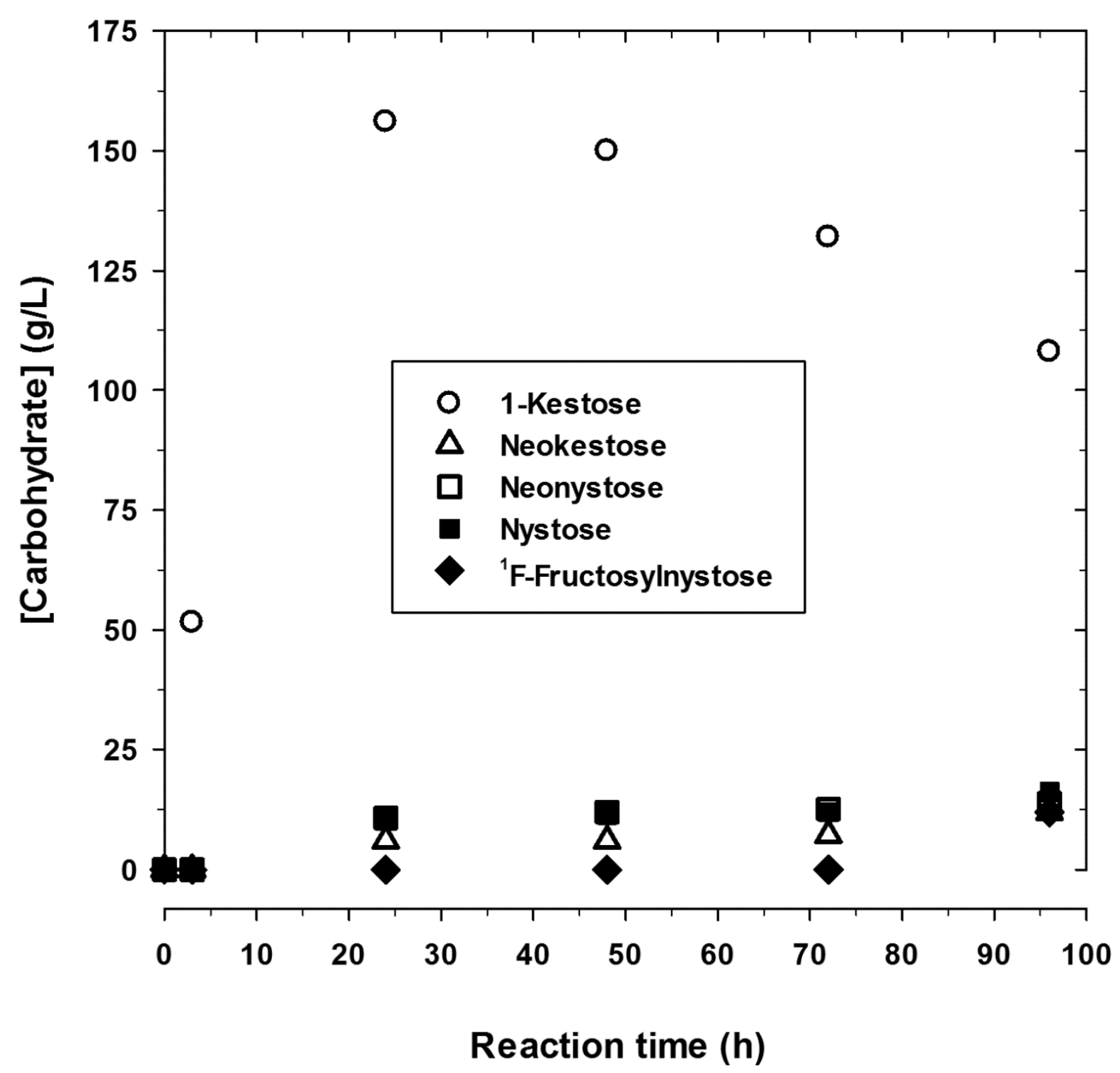

